\title{
Pelatihan Penerapan Media Pembelajaran Daring dalam Upaya Peningkatan Kompetensi Guru Sekolah Dasar Islam Terpadu Al-Ikhlas
}

\author{
Syafi'ul Hamidani*1, Robi Yanto², Veradilla Amalia3 ${ }^{3}$ Endang Etriyanti4
}

\author{
1,2,3,4Sistem Informasi, STMIK Bina Nusantara Jaya Lubuklinggau, Indonesia \\ *e-mail: $\underline{\text { hamidanipertama@gmail.com }}{ }^{1}$ wrtech30@gmail.com ${ }^{2}{ }^{\text {veradillaamalia@gmail.com }}{ }^{3}$. \\ endang.etriyanti@gmail.com ${ }^{4}$
}

\begin{abstract}
Abstrak
Media pembelajaran secara daring dalam proses pembelajaran pada masa pandemi COVID-19 ini merupakan cara yang paling efektif agar proses pembelajaran tetap terus berjalan. Namun kendala yang dihadapi tentunya tidak hanya tuntutan perubahan metode pembelajaran namun perlu waktu, biaya dan pemilihan media yang tepat. Program pengabdian pada masyarakat ini memiliki tujuan untuk mengenalkan penggunaan media pembelajaran yang dapat menjadi alternatif bagi para guru dan dapat diimplementasikan dalam proses pembelajaran dalam masa pandemi COVID-19. Pengabdian kepada masyarakat yang dilakukan ialah memberikan pelatihan penerapan media pembelajaran menggunakan Zoom Meeting dan Google Clasroom yaitu bagaimana proses share materi ajar bahkan sampai proses pembuatan soal-soal ujian baik ujian harian, tengah semester bahkan ujian akhir semester yang diterapkan secara daring. Peserta pengabdian adalah guru-guru Sekolah Dasar Islam Al-Ikhlas Kota Lubuklinggau. Untuk kepentingan layanan pengabdian dan ketersediaan sarana dan prasaranan maka diambil 12 orang guru. Pelatihan diadakan secara langsung dengan melalui pelatihan penerapan media pembelajaran secara online menggunakan Zoom Meeting dan Google Classroom adapun kegiatan pelatihan dilaksanakan pada tanggal 12 Agustus s/d 14 Agustus 2020. Pelaksanaan pengabdian secara umum dapat dikategorikan berhasil dari segi partisipasi peserta mengingat dari 12 target peserta yang diundang yang mengikuti pelatihan melalui video conference sebanyak 12 orang. Peserta sangat antusias dengan kegiatan pengabdian ini sangat bermanfaat untuk mendukung proses belajar yang dilaksanakan oleh sekolah dasar dan peserta akan menggunakan Zoom Meeting dan Google Classroom dalam proses pembelajaran. Respon peserta atas kegiatan pengabdian yang dilaksanakan menyatakan bahwa dari kualitas pemateri, kualitas modul adalah sangat baik.
\end{abstract}

Kata kunci: Google Classroom, Media Pembelajaran, Zoom Meeting

\begin{abstract}
Online learning media in the learning process during the COVID-19 pandemic is the most effective way to keep the learning process going. However, the obstacles faced are of course not only the demands for changes in learning methods but also the time, cost and selection of the right media. This community service program has the aim of introducing the use of learning media that can be an alternative for teachers and can be implemented in the learning process during the COVID-19 pandemic. Community service that is carried out is providing training on the application of learning media using Zoom Meetings and Google Classroom, namely how to share teaching materials and even the process of making exam questions, both daily exams, mid-semester and even end-semester exams that are applied online. The service participants were teachers from the Al-Ikhlas Islamic Elementary School, Lubuklinggau City. For the sake of community service and the availability of facilities and infrastructure, 12 teachers were taken. The training was held directly through training on the application of online learning media using Zoom Meetings and Google Classroom while the training activities were carried out on August 12 to August 14, 2020. The implementation of service in general can be categorized as successful in terms of participant participation considering that from the 13 target participants who were invited to take part in the training through video conferences as many as 12 people. Participants are very enthusiastic about this service activity which is very useful to support the learning process carried out by elementary schools and participants will use Zoom Meetings and Google Classroom in the learning process. Participants' responses to the service activities carried out stated that from the quality of the presenters, the quality of the modules was very good.
\end{abstract}

Keywords: Google Classroom, Instructional Media, Zoom Meeting 


\section{PENDAHULUAN}

Kegiatan pembelajaran adalah proses komunikasi dua arah yang melibatkan antara guru dengan siswa. Proses komunikasi ini terdiri atas kegiatan penyampaian pesan (materi pembelajaran) antara pengirim (guru) kepada penerima (siswa). Penyampaian pesan membutuhkan penggunaan media yang tepat agar pembelajaran dapat berjalan dengan efektif dan efisien. Dimasa pandemi ini tentunya banyak terjadi adaptasi dan perubahan yang mengharuskan kita untuk dapat menyesuaikan diri terutama tuntutan proses adapatasi pembelajaran yang selama ini dilakukan secara luring menuntut kita untuk menerapkan proses belajar secara daring atau online, Oleh karena itu, media pembelajaran menjadi cukup penting karena tanpa media maka komunikasi tidak akan terjadi dan proses pembelajaran tidak akan berlangsung optimal.

Dari banyak pengertian media pembelajaran yang banyak dikemukakan oleh ahli, menurut Rossi dan Breidle (Sanjaya, 2013) bahwa media pembelajaran adalah seluruh alat dan bahan yang dapat dipakai untuk mencapai tujuan pendidikan seperti radio, televisi, buku, koran, majalah, internet dan sebagainya.

Pentingnya media pembelajaran dalam menunjang proses pembelajaran seringkali terabaikan oleh guru dengan berbagai alasan. Misalnya saja sebagaimana dikemukakan oleh Zainal Muttaqien (Muttaqien, 2011) bahwa muncul berbagai alasan belum digunakannya media pembelajaran yang tepat oleh guru. Diantaranya terbatasnya waktu untuk mempersiapkannya, sulit mencari media yang tepat, dan juga tidak tersedianya cukupdana.

Media pembelajaran dan teknologi informasi dalam sistem belajar mengajar mempunyai fungsi yang sangat penting. Sebab tidak semua pengalaman belajar dapat diperoleh secara langsung. Media pembelajaran dapat digunakan agar lebih memberikan pengetahuan yang kongkret dan tepat serta mudah dipahami.

Media pembelajaran mempunyai kegunaan, antara lain (Daryanto, 2011):

a. Memperjelas pesan agar tidak terlaluverbalistis.

b. Mengatasi keterbatasan ruang, waktu, tenaga, dan dayaindra.

c. Menimbulkan gairah belajar, interaksi lebih langsung antara siswa dengan sumber belajar.

d. Memungkinkan siswa belajar mandiri sesuai dengan bakat dan kemampuan visual, auditori, dan kinestetiknya.

e. Memberi rangsangan, mempersamakan pengalaman, dan menimbulkan persepsi yang sama.

Sedangkan menurut Levie \& Lentz mengemukakan empat fungsi media pembelajaran, khususnya media visual, yaitu (Arsyad, 2007) :

a. Fungsi atensi. Fungsi atensi media visual merupakan inti, yaitu menarik dan mengarahkan perhatian siswa untuk berkonsentrasi kepada isi pelajaran yang berkaitan dengan makna visual yang ditampilkan atau menyertai teks materi pelajaran.

b. Fungsi afektif. Dapat terlihat dari tingkat kenikmatan siswa ketika belajar (atau membaca) teks yang bergambar. Gambar atau lambang visual dapat menggugah emosi dan sikapsiswa.

c. Fungsi kognitif. Terlihat dari temuan-temuan penelitian yang mengungkapkan bahwa lambang visual atau gambar memperlancar pencapaian tujuan untuk memahami dan mengingat informasi atau pesan yang terkandung dalamgambar.

d. Fungsi kompensatoris. Media pembelajaran berfungsi untuk mengakomodasikan siswa yang lemah dan lambat menerima dan memahami isi pelajaran yang disajikan dengan teks atau disajikan secara verbal.

Proses pembelajaran mengandung lima komponen komunikasi, guru (komunikator), bahan pembelajaran, media pembelajaran, siswa (komunikan), dan tujuan pembelajaran. Jadi media pembelajaran adalah segala sesuatu yang dapat digunakan untuk menyalurkan pesan (bahan pembelajaran), sehingga dapat merangsang perhatian, minat, pikiran, dan perasaan siswa dalam kegiatan belajar untuk mencapai tujuan belajar.

Seiring dengan perkembangan teknologi informasi dan komunikasi dan dampak nyata yang diakibatkan pandemi COVID-19 maka guru dituntut untuk dapat memanfaatkan internet sebagai media pembelajaran dan penunjang proses pembelajaran yang optimal. Sehingga alasan-alasan yang dikemukakan diatas dapat dicarikan solusinya dengan pemanfaatan internet. 
Dengan layanan perangkat yang beragam dan berbasis IT, guru dan siswa dapat mengaksesnya secara online dan terdapat banyak aplikasi yang bersifat gratis untuk pengguna. Diantaranya adalah penggunaan Zoom Meeting danGoogle Classroom sebagai media pembelajaran.

Para guru juga dapat memanfaatkan Zoom Meeting dan Google Classroom sebagai media alternatif penyampaian pengetahuan dan media pembelajaran online untuk mengatasi masalah yang ditimbulkan oleh dampak pandemi COVID-19 ini. Adapun kegiatan penerapan pembelajaran daring baik secara Syncronous maupun Asyncronus. Salah satu aplikasi synchronous yaitu Zoom Meeting yang memungkin guru dan siswa dapat bertatap muka secara virtual dan dapat mengshare materi dalam pertemuan secara online tersebut, dan salah satu aplikasi Asyncronus yaitu Google Classroom yang dapat dimanfaatkan untuk berbagi materi pembelajaran oleh guru yang dapat diakses kapanpun dan dimanapun oleh siswa. Google Classroom juga dapat digunakan sebagai media interaksi dan diskusi antara guru dan siswa dan juga google classrom dapat dimanfaatkan guru sekolah dasar untuk melaksanakan harian, tengah semseter dan semester secara online.

Zoom Meeting dan Google Classroom yang akan digunakan sebagai media pembelajaran oleh siswa dan guru juga dapat dengan mudah diakses menggunakan bantuan semua jenis sistem operasi. Mengingat saat ini semakin banyaknya pengguna perangkat yang menggunakan beragam jenis sistem operasi. Siswa maupun guru dapat memanfaatkan aplikasi dalam android untuk mengakses materi pembelajaran yang mereka miliki dimanapun dan kapanpun.

Berdasarkan pada uraian di atas, maka dapat diidentifikasi masalah program pengabdian pada masyarakat adalah belum diterapkannya media pembelajaran Zoom Meeting dan Google Classroom yang tepat oleh guru. Diantaranya dikarenakan terbatasnya waktu untuk mempersiapkannya, sulit mencari media yang tepat. Dan upaya-upaya apa yang dilakukan untuk menerapkan media pembelajaran Zoom Meeting dan Google Classroom guna menunjang proses pembelajaran antara siswa dengan guru di SD IT Al-Ikhlas kota lubuklinggau.

\section{METODE}

Kegiatan pengabdian ini dimulai dengan analisa permasalahan yang timbul di SD IT Alikhlas Kota Lubuklinggau. Kemudian dilanjutkan dengan penyusunan rancangan tahapan kegiatan. Adapun kegiatan pengabdian kepada masyarakat terdiri atas beberapa tahap yaitu:

a. Analisa Permasalahan dan kebutuhan para guru SD IT Al-ikhlas Kota Lubuklinggau, yang dalam hal ini ditemukan masalahnya adalah keterbatasan media pembelajaran dalam kondisi pandemi COVID-19.

b. Pengenalan berbagai media pembelajaran yang cocok untuk para guru SD IT Al-ikhlas Kota Lubuklinggau dan pengenalan zoom dan Google Classroom sebagai media pembelajaran.

c. Diskusi dan praktek penerapan Zoom Meeting dan Google Classroom.

Adapun kerangka pemikiran dari pemecahan masalah adalah sebagai berikut.

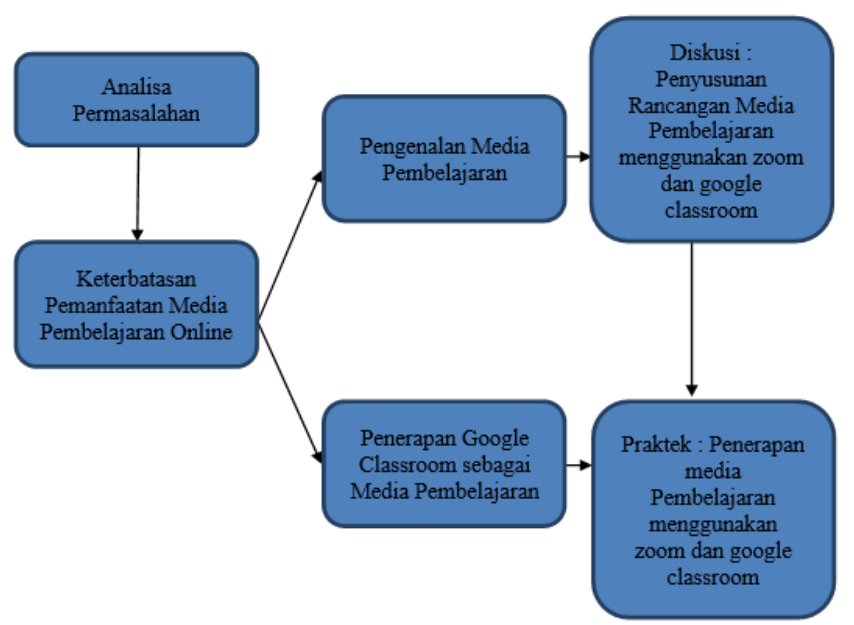

Gambar 1. Kerangka Pemecahan Masalah 


\section{HASIL DAN PEMBAHASAN}

Pengabdian Secara umum kegiatan pengabdian ini berjalan lancar, dimulai dari kegiatan survey pendahuluan, pelaksanaan kegiatan pengabdian, sampai kepada penyusunan laporan. Pelaksanaan kegiatan berjalan lancar terlihat dari tingkat kehadiran peserta, aktifnya saat berdiskusi dan banyaknya pertanyaan yang dilontarkan pada saat sesi tanya-jawab kepada tim pengabdi. Hal ini dikarenakan para peserta menyadari bahwa di era teknologi informasi, pembelajaran secara online merupakan salah satu sarana penting dalam menyampaikan materi pelajaran kepada siswa sekolah.

Melalui pengabdian yang berkelanjutan akan terjalin hubungan kerja sama UPPM STMIK Bina Nusantara Jaya Lubuklinggau dengan guru-guru Sekolah Dasar Islam Terpadu Al-Ikhlas Kota Lubuklinggau. Hubungan kerjasama dalam hal pengembangan metode pembelajaran bagi guru-guru sehingga program pengabdian masyarakat dapat berjalan maksimal, yang menjadi salah satu kewajiban civitas akademika.

Pengabdian pada masyarakat dilaksanakan selama 3 hari, yang setiap harinya diberikan pre tes dan post test untuk mengukur perkembangan peserta pelatihan, dan didapatlah hasil seperti table berikut.

Tabel 1. Nilai Pre test dan post test

\begin{tabular}{cccc}
\hline $\begin{array}{c}\text { Hari } \\
\text { Pelaksanaan }\end{array}$ & $\begin{array}{c}\text { Jumlah } \\
\text { Peserta }\end{array}$ & $\begin{array}{c}\text { Nilai rata rata benar } \\
\text { pre test }\end{array}$ & $\begin{array}{c}\text { Nilai rata rata benar } \\
\text { post test }\end{array}$ \\
\hline Hari Pertama & 12 orang & $41,66 \%$ & $56,66 \%$ \\
Hari Kedua & 12 orang & $23,33 \%$ & $43,33 \%$ \\
Hari Ketiga & 12 orang & $25 \%$ & $41,66 \%$ \\
\hline
\end{tabular}

Dari table diatas dapat dilihat bahwa nilai rata rata benar peserta pelatihan mengalami peningkatan setiap harinya dengan demikian dapat dikatan bahwa kegiatan pelatihan ini berhasil.

Pelaksanaan kegiatan ini dilakukan 3 hari dengan jumlah jam pelaksanaan tiap harinya adalah 4 jam pelaksanaan dan total jam pelaksanaan selama 4 hari adalah 12 jam pelaksanaan. penjelasan pelaksanaan tiap pengabdian adalah sebagai berikut:

\subsection{Pelaksanaan Hari Pertama}

Pelaksanaan pengabdian pada hari pertama terfokus pada penyampaian teori yang terkait dengan materi PPM. Materi disampaikan dalam dua sesi yang diselingi dengan waktu istirahat. Sesi pertama, materi yang disampaikan adalah: Pengertian Media Pembelajaran, Peran dan Fungsi Media Pembelajaran, Taksonomi Media Pembelajaran, dan Karakteristik Media Pembelajaran. Sedangkan pada sesi kedua, materi yang disampaikan adalah Pengembangan dan Evaluasi Media Pembelajaran. Dengan narasumber Robi Yanto, M.Kom. dan Endang Etriyanti, M.Kom.

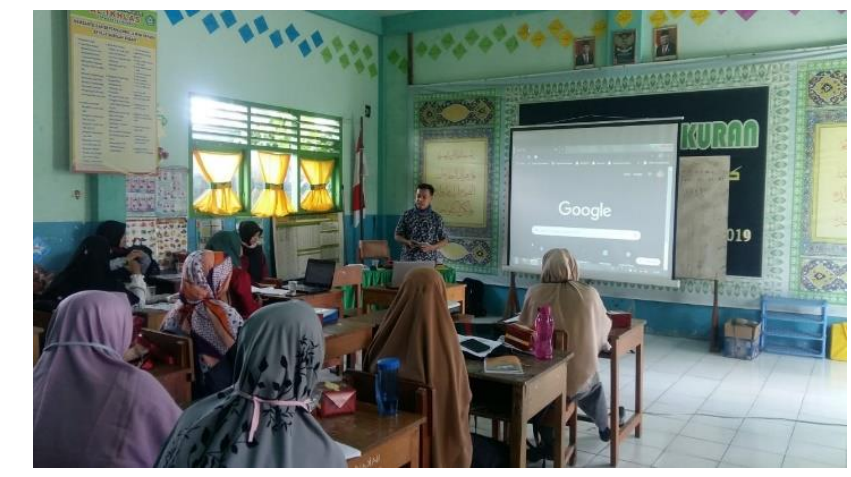

Gambar 2. Penyampaian Materi Media Pembelajaran 


\subsection{Pelaksanaan Hari Kedua}

Pelaksanaan pengabdian pada hari kedua terfokus pada praktik pembuatan media pembelajaran. Sesi praktikum diadakan dalam dua sesi yang diselingi dengan waktu istirahat. Sesi pertama, praktikum terkait tentang pembuatan media menggunakan Google Classroom. Sedangkan pada sesi kedua, praktikum terkait pembuatan media pembelajaran menggunakan Google Classroom. Dengan narasumber Veradilla Amalia, M.Kom. dan Syafi'ul Hamidani, M.Kom.

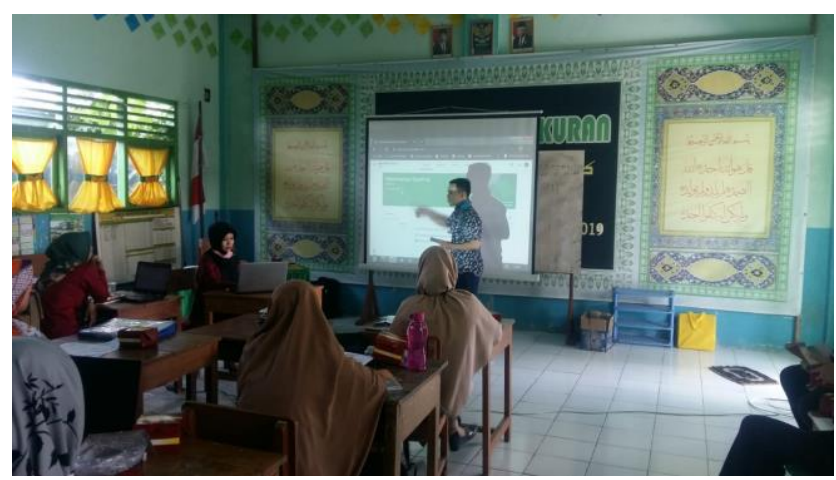

Gambar 3. Penyampaian Materi Google Classroom

\subsection{Pelaksanaan Hari Ketiga}

Pelaksanaan pengabdian pada hari ketiga terfokus pada kegiatan pendampingan pembuatan bahan ajar media pembelajaran secara online. Pada sesi pendampingan ini, guruguru secara mandiri membuat bahan ajar yang nantinya akan digunakan pada media pembelajaran online yaitu Zoom Meeting. Sesi pendampingan pembuatan bahan ajar media pembelajaran diadakan dalam dua sesi yang diselingi dengan waktu istirahat. Sesi pertama, pendampingan terkait tentang pembuatan bahan ajar media pembelajaran. Sedangkan pada sesi kedua merupakan lanjutan dari sesi pertama yang belum tuntas. Dengan narasumber Endang Etriyanti, M.Kom. dan Veradilla Amalia, M.Kom.

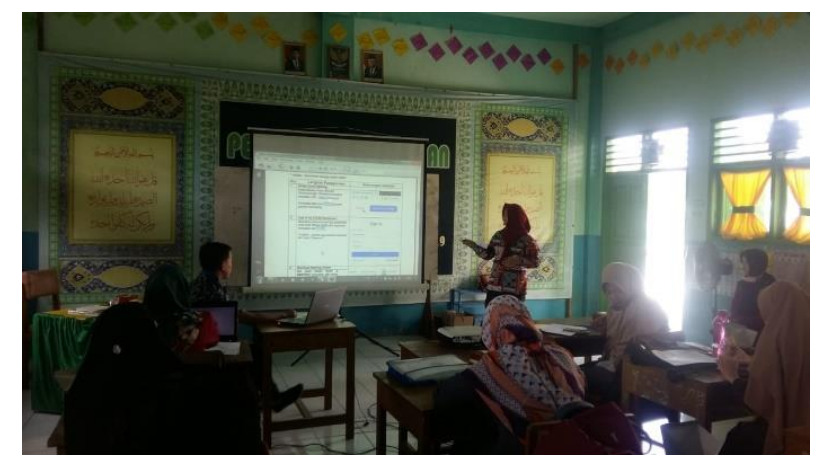

Gambar 4. Penyampaian Materi Zoom Meeting

\section{KESIMPULAN}

Berdasarkan uraian pelaksanaan kegiatan pengabdian ini, maka dapat ditarik kesimpulan adalah kegiatan pengabdian ini dapat dikategorikan berhasil dari segi partisipasi peserta mengingat dari 12 calon target peserta yang diundang yang hadir sebanyak 12 orang. Dan Para peserta merasa kegiatan pengabdian ini sangat bermanfaat bagi mereka, karena sebagai pendidik mereka merasa perlu untuk mengembangkan media pembelajaran menggunakan Google Classroom sebagai media penyampai pesan pembelajaran. Media ini dapat membantu pendidik dalam memadukan pembelajaran melalui online dan tatap muka (konvensional) sehingga dapat saling melengkapi. Hal tersebut juga memberikan pengalaman belajar baru bagi siswa akibat dari dampak pandemi COVID-19 sehingga proses belajar mengajar dapat terus bisa dilaksanakan. 


\section{DAFTAR PUSTAKA}

Arsyad, A. (2007). Media Pembelajaran. Raja Grafindo Persada.

Daryanto, D. (2011). Media Pembelajaran. PT Sarana Tutorial Nurani Sejahtera.

Muttaqien, Z. (2011). Pemanfaatan Blog sebagai Media dan Sumber Belajar Alternatif Qur'an Hadits Tingkat Madrasah Aliyah. Program Pascasarjana UIN Sunan Kalijaga.

Sanjaya, W. (2013). Strategi Pembelajaran Berorientasi Standar Proses Pendidikan. Kencana Prenada Media Group. 